\title{
1 Dosage effects of Waxy gene on the structures and properties of corn starch
}

2

3 Hanyu Yangcheng, ${ }^{1}$ Michael Blanco, ${ }^{2}$ Candice Gardner, ${ }^{2}$ Xuehong Li, ${ }^{1,3}$ Jay-lin Jane ${ }^{1, *}$

4

$5 \quad{ }^{1}$ Department of Food Science and Human Nutrition, Iowa State University, Ames, IA 50011

6 USA;

$7 \quad{ }^{2}$ USDA-ARS Plant Introduction Research Unit, and Department of Agronomy, Iowa State

8 University, Ames, IA 50011, USA;

$9{ }^{3}$ Department of Food Science and Bioengineering, Zhengzhou University of Light Industry,

10 Zhengzhou, Henan, China

11

$12 *$ Corresponding author:

13 Tel: 01 515-294-9892; Fax: 01 515-294-8181;

14 E-mail address: jjane@iastate.edu (J.Jane) 


\section{Abstract}

The objective of this study was to understand dosage effects of the Waxy gene on the

17 structures of amylose and amylopectin and on the properties of corn starch. Reciprocal crossing

18 of isogenic normal and waxy corn lines was conducted to develop hybrids with different dosages

$19(0,1,2,3)$ of Waxy gene in the endosperm. The amylose content of starch and proportions of

20 branch chains of DP 17-30 and extra-long branch chains (DP > 100) of amylopectin were

21 positively correlated with the Waxy-gene dosage. Proportions of short (DP $<17)$ and long

22 branch-chains (DP 30-80), however, were negatively correlated with the Waxy-gene dosage. The

23 gelatinization conclusion-temperature and temperature-range of the starch were negatively

24 correlated with the Waxy-gene dosage, indicating that amylose facilitated dissociation of the

25 surrounding crystalline regions. These results helped us understand the function of granule-

26 bound starch synthase I in the biosynthesis of amylose and amylopectin and impacts of Waxy-

27 gene dosages on the properties of corn starch.

28

29 Keywords: Waxy gene; dosage effects; branch-chain length distribution; starch properties 


\section{Introduction}

Corn (Zea mays L.) is the largest crop produced worldwide, followed by rice and wheat (FAOSTAT, 2012). Most of the corn is used for livestock feed, and the remaining is processed for many food and industrial applications, including corn meal, corn starch, corn syrup and highfructose corn syrup, alcoholic beverage, and fuel ethanol, etc. (USDA ERS, 2015). Starch is the major component of corn kernels ( $\sim 72 \%$ by dry mass) and the energy source for food, feed, and ethanol fuel. Starch of normal (wild type) corn consists of two glucans: amylose and amylopectin. Amylose is primarily a linear polysaccharide of D-glucopyranose units connected by $\alpha-1,4$

glycosidic bonds with few $\alpha-1,6$ linked branches (Takeda, Tomooka, \& Hizukuri, 1993).

Amylopectin is a highly branched polysaccharide, in which the short linear-chains are connected by $\alpha-1,6$ glycosidic branch linkages (Tester, Karkalas, \& Qi, 2004).

Waxy corn is a naturally occurring corn mutant, and the starch of waxy corn consists of almost exclusively amylopectin. Compared with normal corn starch, waxy corn starch provides unique functions for many food and non-food applications. For example, waxy corn starch is preferably used in frozen foods to improve the freeze-thaw stability, and in textile, corrugating, and adhesive industries because of its clear film-forming property (Fergason, 1994). Waxy corn can be preferred as livestock feed because of its good feed-conversion efficiency resulting from the greater digestibility of the waxy starch (Collins, Moran, \& Stillborn, 2003).

The endosperm of waxy corn kernels lacks the enzyme activity of granule-bound starch synthase I (GBSSI) encoded by the Waxy gene (Denyer, Johnson, Zeeman, \& Smith, 2001). The GBSSI, with a molecular weight of 58-60 kDa, is the only known enzyme responsible and required for the biosynthesis of amylose molecules in corn (Denyer et al. 2001). It has been reported that GBSSI is also involved in the biosynthesis of extra-long branch-chains of 
53 amylopectin in various plants, such as wheat (Yoo \& Jane, 2002a), rice (Hanashiro et al., 2008),

54 and sweet potato (Kitahara et al., 2007). Some other studies using near-isogenic waxy and non-

55 waxy wheat, however, showed contradictory results: non-waxy wheat starch consisted of no

56 extra-long branch-chains and GBSSI showed no effects on the branch-chain length distribution

57 of amylopectin (Miura, Wickramasinghe, Subasinghe, Araki, \& Komae, 2002; Yasui, Ashida, \&

58 Sasaki, 2009). Yasui et al. (2009) argued that the extra-long branch-chains of amylopectin in

59 normal or non-waxy starches were possibly contamination of amylose molecules resulting from

60 incomplete separation of the amylose from amylopectin molecules.

61 The endosperm tissue of corn has three sets of chromosomes, two sets from maternal

62 parent and one set from pollen parent (Darrah, McMullen, \& Zuber, 2003). Therefore, for a

63 single gene, there could be four different dosages of the gene $(0,1,2,3)$ in the endosperm. The

64 dosage effects of Waxy gene on the structures and properties of corn starch are not fully

65 understood, and the effects of GBSSI on the biosynthesis of extra-long branch-chains are still

66 being debated.

67 The objective of this study was to understand the dosage effects of Waxy gene on the

68 structures of amylose and amylopectin of corn starch and on starch properties. Results obtained

69 from this study will add to the understanding of the physiological function of GBSSI in the

70 biosynthesis of starch molecules and the properties of starch with different dosages of Waxy gene.

71 Understanding properties of starch with different Waxy-gene dosages can facilitate developments

72 of value-added utilizations of waxy and partial-waxy corn starch.

73

74 2. Materials and Methods

$75 \quad 2.1$ Materials 
Isogenic normal and waxy corn lines were used in this study to minimize the interference

77 of different genetic background. Two sets of isogenic normal and waxy corn lines were used as

parent lines. The Set 1 samples included the pedigree DKXL370:N11a20-036-002, and the Set 2 samples included the pedigree AR16035:S02-615-001. The normal corn used in this study was at the S6 level of inbreeding (6 generations of self-pollination). The isogenic waxy corn was developed by crossing the normal corn to a waxy corn and backcrossing to the normal inbred for five generations (BC5). Selection for the waxy phenotype was made at each generation.

Reciprocal crossing between the isogenic normal and waxy corn were conducted to develop corn lines with different dosages of the Waxy gene in the endosperm: waxy $\times$ waxy $(0$ dosage), waxy $\times$ normal $(1$ dosage $)$, normal $\times$ waxy $(2$ dosages $)$, and normal $\times$ normal $(3$ dosages $)$. All the corn lines were developed within the USDA-ARS Germplasm Enhancement of Maize (GEM) Project and grown at the North Central Regional Plant Introduction Station farm (Ames, IA) in 2014. For each genotype, two rows of corn plants ( $\sim 10$ plants each row) were grown and all the corn ears with the same genotype were harvested and pulled together in bulk. Corn ears were dried to approximately $12 \%$ moisture and shelled. The pedigree, genotype, and the dosage of Waxy gene in the endosperm of the corn lines are listed in Table 1.

Pseudomonas isoamylase (EC 3.2.1.68, $280 \mathrm{U} / \mathrm{mg}$ ) was purchased from Megazyme International Ireland (Wicklow, Ireland). All other chemicals were reagent grade and were purchased from either Sigma-Aldrich Co. (St. Louis, MO) or Fisher Scientific (Pittsburgh, PA) and used without further purification.

\subsection{Starch Isolation by Wet-Milling}

Starches were isolated from the corn kernels using a wet-milling method reported by Li, Jiang, Campbell, Blanco, \& Jane (2008). 


\subsection{Amylose Content of Starch}

The amylose content of the corn starch was determined using an iodine potentiometricautotitrator (702 SM Titrino, Brinkmann Instrument, Westbury, NY) using a method reported by Song \& Jane (2000). Lipids of the starch were removed using $85 \%$ methanol in a Soxhlet extractor for $16 \mathrm{~h}$ prior to the analysis. The iodine affinity of amylose used for the calculation was 0.2 (Takeda \& Hizukuri, 1987). The amylose content was calculated using the equation:

Amylose $(\%)=100 \% \mathrm{IA}_{\mathrm{s}} / 0.2$, where $\mathrm{IA}_{\mathrm{s}}$ was the iodine affinity of the starch.

\subsection{Lipid Content of Starch}

Lipids of the starch were extracted following the AOAC method 996.06 (2000). The lipid content of the starch was determined gravimetrically after removal of the solvent and calculated using the equation:

$$
\text { Lipid }(\%)=\text { Weight of extracted lipids / Weight of the starch }(\mathrm{db}) \times 100 \% \text {. }
$$

\subsection{Fractionation of Amylose}

Amylose of the starch was separated from amylopectin using 1-butanol, following the method reported by Jane \& Chen (1992) and Schoch (1942). Dispersed starch in an aqueous medium $(1 \%, \mathrm{w} / \mathrm{v})$ was mixed with 1-butanol $(20 \%, \mathrm{v} / \mathrm{v})$ and refluxed under mechanical stirring in a boiling-water bath for $1 \mathrm{hr}$. The mixture in a sealed flask was place in a Duwar flask filled with boiling water, and the Duwar flask was sealed and allowed to slowly cool down to room temperature over 24-30 hr. During the cooling process, amylose formed helical complex with 1butanol, which crystallized and precipitated from the starch dispersion. Amylopectin molecules, however, remained in the supernatant.

\subsection{Average Molecular-Weight of Amylose}

Molecular-weight distribution of the isolated amylose was determined using a highperformance size-exclusion chromatography (HPSEC) following the method of Jiang, Campbell, 
123 Blanco, \& Jane (2010). The HPSEC system consisted of a Prostar 210 pump (Varian, Walnut

124 Creek, CA), a refractive-index detector (Prostar 355, Varian, Walnut Creek, CA), and Shodex

125 SB-804 and SB-803 analytical columns (Showa Denko K.K., Tokyo, Japan). The temperature of

126 the columns was maintained at $50{ }^{\circ} \mathrm{C}$ in a column oven (Prostar 510, Varian, Walnut Creek, CA).

127 The mobile phase was degassed and distilled-deionized water at a flow rate of $0.5 \mathrm{ml} / \mathrm{min}$.

128 Maltose, maltotriose, maltotetraose, maltohepaose, and pullulan standards (P10, P20, P100,

129 Showa Denko K.K., Tokyo, Japan) were used as references to make a standard curve between

130 the elution time and molecular weight. The weighted mean of the molecular weight of amylose

131 was calculated by using the refractive-index value as the weight.

132

133

134

135

136

137

138

139 140 deionized water at a flow rate of $0.5 \mathrm{ml} / \mathrm{min}$.

141

142

143

144

145

\subsection{Amylopectin Branch-Chain Length Distribution}

\subsection{Molecular Weight and Gyration Radii of Amylopectin}

Molecular weight and gyration radii of the amylopectin were determined using a HPSEC equipped with a multi-angle laser-light scattering detector (Dawn DSP-F, Wyatt Tech. Corp., Santa Barbara, CA) and a refractive-index detector (HP 1047A, Hewlett Packard, Valley Forge, PA) following the method of Yoo \& Jane (2002b). Shodex SB-806 and SB-804 analytical columns (Showa Denko K.K., Tokyo, Japan) were used to separate amylopectin from amylose. The temperature of the columns was maintained at $50{ }^{\circ} \mathrm{C}$ using a $\mathrm{CH}-460$ column heater and a TC-50 controller (Eppendorf, Madison, WI). The mobile phase was degassed and distilled-

Amylopectin of the corn starch was separated from amylose using a gel-permeation chromatographic column packed with Sepharose CL-2B gel. The isolated amylopectin was debranched using Pseudomonas isoamylase (Megazyme International Irelands, Wicklow, Ireland) following the method of Li, et al. (2008). Branch-chain length distribution of the debranched 
amylopectin was analyzed using a HPSEC following the method of Jiang, et al. (2010). The HPSEC system consisted of a Prostar 210 pump (Varian, Walnut Creek, CA), a refractive-index detector (Prostar 355, Varian, Walnut Creek, CA), and a Shodex SB-803 analytical column (Showa Denko K.K., Tokyo, Japan). The temperature of the columns was maintained at $50{ }^{\circ} \mathrm{C}$ in a column oven (Prostar 510, Varian, Walnut Creek, CA). The mobile phase was degassed and distilled-deionized water at a flow rate of $0.5 \mathrm{ml} / \mathrm{min}$.

\subsection{Thermal Properties of the Starch}

Thermal properties of the starch were analyzed using a differential scanning calorimeter (DSC, Diamond, Perkin-Elmer, Norwalk, CT). Starch samples in excess water (starch $:$ water $=1$ : $3, \mathrm{w} / \mathrm{v}$ ) were heated in a DSC from 20 to $110^{\circ} \mathrm{C}$, at a heating rate of $10^{\circ} \mathrm{C} / \mathrm{min}$. The gelatinization onset $\left(\mathrm{T}_{\mathrm{o}}\right)$, peak $\left(\mathrm{T}_{\mathrm{p}}\right)$, and conclusion temperatures $\left(\mathrm{T}_{\mathrm{c}}\right)$ and enthalpy change $(\Delta H)$ of the starch were determined using a Pyris software (Perkin-Elmer).

\subsection{Pasting Properties of the Starch}

Pasting properties of the starch in an aqueous suspension $(8 \%, \mathrm{w} / \mathrm{w}, \mathrm{db})$ were analyzed using a rapid visco-analyzer (Newport Scientific, Sydney, Australia) following the method of Jane, et al. (1999). The pasting temperature, and the peak, breakdown, and final viscosities were determined using the Thermocline software (Newport Scientific).

\subsection{Statistical Analysis}

Data were subjected to ANOVA and Tukey's multiple comparison analysis using PROC ANOVA procedure of SAS 9.4 (SAS Institute, Inc., Cary, NC). The normality of data for each variable was investigated using the PROC UNIVARIATE procedure. Because the dosage of waxy gene and most of the other variables were not normally distributed (data not shown), a Spearman correlation test was used to analyze correlations between the waxy gene dosage and 
169 the physicochemical properties of the starch. Statistical significance was declared at $p<0.05$ if 170 without further indication.

172 3. Results and Discussion

$173 \quad 3.1$ Content and Average Molecular-Weight of Amylose

Amylose contents and amylose molecular-weights of starches from corn with different

175 dosages of Waxy gene are shown in Table 2. The amylose contents ranged from 1.6 to $27.9 \%$ for 176 the Set 1 samples and from 0.0 to $26.6 \%$ for the Set 2 samples. The amylose content was

177 positively correlated with the dosage of Waxy gene $(\mathrm{r}=0.98, \mathrm{p}<0.01)$, which was in line with

178 the effects of Waxy-gene dosages on wheat starch (Miura et al. 2002; Wichramasinghe \& Miura, 179 2003). The increase in the amylose content, however, was not proportional to the increase in the 180 dosage of Waxy gene in the endosperm. For example, the relative amylose content increased by 18169 or $75 \%$, using the amylose content of the isogenic normal corn starch as the reference $(100 \%)$, 182 when the Waxy-gene dosage increased from 0 to 1 in the endosperm, whereas further increase in 183 the Waxy-gene dosage from 1 to 2 only showed small increase in the relative amylose content by 1845 or $6 \%$ (Table 2). These results were in line with that previously reported (Tsai, 1974).

Average molecular-weight of the isolated amylose ranged from DP 629.8 to 651.3 for the

186 Set 1 samples, and from DP 637.8 to 646.1 for the Set 2 samples (Table 2). There were no

187 significant differences in the average molecular-weight of amylose between the starch samples 188 with different dosages of the Waxy gene in the endosperm. The molecular-weight distribution of 189 amylose as indicated by the HPSEC chromatograms (data not shown) displayed no differences 190 with different dosages of the Waxy gene in the endosperm. These results indicated that the Waxy 191 gene had little effects on the molecular weight of amylose.

$192 \quad 3.2$ Lipid Content of Starch 
Lipid contents of the starch samples are shown in Table 2. The waxy corn starches

consisted of little lipids ( $0.24 \%$ for the Set 1 waxy corn and $0.10 \%$ for the Set 2 waxy corn). Lipid contents of the partial-waxy and normal corn starches ranged from 0.71 to $0.84 \%$ for the Set 1 samples and from 0.55 to $0.84 \%$ for the Set 2 samples. The correlation coefficient between the amylose and lipid contents of the starch samples was $0.75(p=0.086)$.

\subsection{Molecular Weight of Amylopectin}

The molecular-weight and gyration radii of amylopectin with different dosages of Waxy gene are shown in Table 3. The amylopectin molecules of the waxy corn starch displayed larger molecular weights and gyration radii than the partial-waxy and normal isogenic corn lines containing 1 to 3 Waxy-gene dosage(s). These results were consistent with that reported on waxy and normal corn, wheat, and potato starches (Bello-Perez, Roger, Baud, \& Colonna, 1998; Yoo \& Jane, 2002b). The correlation coefficient between the molecular weights of amylopectin and amylose contents of the starch samples was -0.66 , and the correlation was moderately significant $(p=0.063)$. For the partial-waxy and normal corn, biosynthesis of amylose competed with that of amylopectin for the substrate of adenosine-5'-diphosphate glucose (ADP-Glu), which resulted in a smaller molecular weight of amylopectin than that of the waxy corn starch (Yoo \& Jane, 2002a).

\subsection{Branch-Chain Length Distribution of Amylopectin}

Branch-chain length distributions of the debranched amylopectin-molecules determined using a HPSEC are shown in Figure 1, and the results are summarized in Table 4. Both sets of the samples showed the same trends in the branch-chain length distribution of amylopectin with different dosages of Waxy gene. The chromatograms showed a major peak at DP $\sim 22$ and two minor peaks at DP $\sim 13$ and DP $\sim 40$ for both sets of samples. For the Set 1 samples, percentages 
of the extra-long branch chains (DP 100-287) increased from $0.2 \%$ to $2.0 \%$, and for the Set 2 samples, percentages of the extra-long branch chains (DP 100-256) increased from $0.3 \%$ to $1.8 \%$ with the increase in the Waxy-gene dosage from 0 to 3 (Table 4). Percentages of the extra-long branch chains were positively correlated with the Waxy-gene dosage $(r=0.93, p<0.01)$. It has been reported that extra-long branch chains are present in partial-waxy and normal starches from various plants, including wheat, rice, and sweet potato (Yoo \& Jane, 2002a; Kitahara, et al. 2007; Hanashiro, et al. 2008), and GBSSI is responsible for the biosynthesis of extra-long branch chains (Denyer, Clarke, Hylton, Tatge, \& Smith, 1996; Hanashiro, et al. 2008). Yasui et al. (2009) postulated that amylose could have been eluted with amylopectin during the GPC separation and the presence of extra-long branch chains could be a result of contamination of the amylose. In this study, the largest detectable chain lengths of extra-long branch chains were DP 287 for the Set 1 samples and DP 256 for the Set 2 samples, which were substantially smaller than the average molecular weight of amylose (DP 629.8-651.3 for the Set 1 samples and DP 637.8-646.1 for the Set 2 samples, respectively) (Table 2). Therefore, the presence of extra-long branch chains was unlikely the contamination of amylose molecules. The positive correlation between the Waxy-gene dosage and the proportion of extra-long branch chains further supported that GBSSI was responsible for the biosynthesis of extra-long branch chains of amylopectin. The HPSEC chromatograms showed that, for both sets of the samples, percentages of the short chains $(\mathrm{DP}<17)(47.3-51.0 \%$ for the Set 1 samples and $46.1-49.9 \%$ for the Set 2 samples) (Table 4) were negatively correlated with the Waxy-gene dosage $(\mathrm{r}=-0.94, \mathrm{p}<0.01)$. Percentages of the intermediate chains of DP 17-30 (30.0-33.5\% for the Set 1 samples and 31.2$37.4 \%$ for the Set 2 samples) were positively correlated with the Waxy-gene dosage $(r=0.86, p<$ 0.01). Percentages of the long branch-chains (DP 30-80) (16.2-17.9\% for the Set 1 samples and 
$14.0-17.8 \%$ for the Set 2 samples) were negatively correlated with the Waxy-gene dosage $(\mathrm{r}=$ $0.76, p<0.05$ ). It was plausible that, with the presence of GBSSI in the partial-waxy and normal corn, the short chains (DP < 17) were elongated to the intermediate chains (DP 17-30). These results also suggested that GBSSI could synthesize the extra-long branch-chains by elongating the long branch-chains (DP 30-80), resulting in decreases in the proportion of the long branchchains in the partial-waxy and normal corn starches. More studies are needed to understand the mechanisms of the effects of GBSSI on the elongation of amylopectin branch-chains.

\subsection{Thermal Properties of Starch}

Starch thermal properties are shown in Table 5. The gelatinization conclusiontemperature $\left(74.4-77.0{ }^{\circ} \mathrm{C}\right.$ for the Set 1 samples and $72.0-74.4{ }^{\circ} \mathrm{C}$ for the Set 2 samples) and temperature-range $\left(8.8-11.2{ }^{\circ} \mathrm{C}\right.$ for the Set 1 samples and $9.5-12.1{ }^{\circ} \mathrm{C}$ for the Set 2 samples) were negatively correlated with the amylose content of starch (Table 2) $(r=-0.91, p<0.05$ for gelatinization conclusion-temperature; $\mathrm{r}=-0.83, \mathrm{p}<0.01$ for gelatinization temperature-range).

These results were in line with that reported on waxy, partial-waxy, and normal wheat starch (Sasaki, Yasui, \& Matsuki, 2000). It is known that gelatinization of starch begins at the hilum of the granule and proceeds radially (Hoseney, Zeleznak, \& Yost, 1986). Amylose is interspersed among amylopectin and is oriented from the hilum to the periphery, extending through multiple clusters of amylopectin molecules (Jane, 2006). During gelatinization of starch, amylose molecules facilitate dissociation of surrounding crystalline clusters of amylopectin, proceeding from the hilum to the periphery, resulting in a lower gelatinization conclusion-temperature and a narrower gelatinization temperature-range (Hoseney, et al. 1986).

\subsection{Pasting Properties of Starch}


Starch pasting properties are shown in Figure 2, and the results are summarized in Table

6. Pasting temperatures of the starch $\left(71.0-73.8^{\circ} \mathrm{C}\right.$ for the Set 1 samples and $69.0-72.5^{\circ} \mathrm{C}$ for the Set 2 samples) had no correlation with the Waxy-gene dosage but were positively correlated $(\mathrm{r}=$

$2640.81, \mathrm{p}<0.01$ ) with the lipid contents of the starch (Table 2). Although there was no correlation 265 between the peak viscosity and the Waxy-gene dosage, the breakdown viscosity was negatively 266 correlated with the Waxy-gene dosage $(\mathrm{r}=-0.83, \mathrm{p}<0.01)$ and the setback viscosity was 267 positively correlated with the Waxy-gene dosage $(\mathrm{r}=0.97, \mathrm{p}<0.01)$. It has been reported that 268 amylose intertwines with amylopectin and maintains the integrity of the starch granule 269 (Hermansson \& Svegmark, 1996; Jane, 2007), which reduces the breakdown of swollen starch270 granules. Amylose participates in gel-network formation during the cooling of the starch paste, 271 resulting in a higher setback viscosity (Deffenbaugh \& Walker, 1989; Jane, et al. 1999; Sasaki, et 272 al. 2000).

\section{Conclusions}

To our knowledge this is the first study to report dosage effects of the Waxy gene on 276 amylopectin branch-chain length distribution in isogenic corn starch. The positive correlation 277 between the Waxy-gene dosage and the percentage of extra-long branch chains supported that 278 GBSSI was responsible for the biosynthesis of extra-long branch chains. GBSSI also increased 279 the proportion of intermediate chains with DP 17-30 and decreased the proportion of short chains 280 with DP $<17$. The Waxy gene showed dosage effects on the amylose content, but no effects on 281 the molecular weight of amylose. The conclusion gelatinization-temperature and gelatinization 282 temperature-range of the starch were negatively correlated with the Waxy-gene dosage, 283 indicating that amylose facilitates dynamic gelatinization of the crystalline structures of 
284 amylopectin. The breakdown viscosity of starch was negatively correlated but the setback

285 viscosity was positively correlated with the Waxy-gene dosage. These results showed that GBSSI

286 was responsible for the biosynthesis of both amylose and amylopectin, which in turn affected the

287 thermal and pasting properties of the starch.

288

289 Acknowledgements

290 The authors thank Dr. Paul Scott for discussions and invaluable suggestions to the

291 manuscript and the USDA-ARS Plant Introduction Research Unit and the GEM project for

292 providing the financial support and the nursery site for the study. 


\section{References}

AOAC. (2000). AOAC official method 996.06, fat (total, saturated, and unsaturated) in foods.

Page 20-24. In Official methods of analysis of AOAC international ( $17^{\text {th }}$ ed.). Maryland: AOAC International.

Bello-Perez, L.A.; Roger, P.; Baud, B.; \& Colonna, P. (1998). Macromolecular features of starches determined by aqueous high-performance size exclusion chromatography. Journal of Cereal Science 27, 267-278.

Collins, N.E.; Moran, E.T.; \& Stillborn, H.L. (2003). Performance of broilers fed normal and waxy corn diets formulated with chick and rooster derived apparent metabolizable energy values for the grains. Journal of Applied Poultry Research 12, 196-206.

Darrah, L.L.; McMullen, M.D.; \& Zuber, M.S. (2003). Breeding, genetics, and seed corn production. In P.J. White \& L.A. Johnson, (Eds.) Corn: Chemistry and Technology, $2^{\text {nd }}$ ed. (pp. 35-68). American Association of Cereal Chemists, Inc., St. Paul, MN.

Deffenbaugh, L.B. \& Walker, C.E. (1989). Comparison of starch pasting properties in the Brabender Viscoamylograph and the Rapid Visco-Analyzer. Cereal Chemistry 66, 493499.

Denyer, K.; Clarke, B.; Hylton, C.; Tatge, H.; \& Smith, A.M. (1996). The elongation of amylose and amylopectin chains in isolated starch granules. The Plant Journal 10, 1135-1143.

Denyer, K.; Johnson, P.; Zeeman, S.; \& Smith, A.M. (2001). The control of amylose synthesis. Journal of Plant Physiology 158, 479-487.

FAOSTAT. (2012). The Statistics Division of the Food and Agriculture Organization. URL: http://faostat3.fao.org/faostat-gateway/go/to/download/Q/QC/E) 
315 Fergason, V. (1994). High amylose and waxy corns. Pages 55-77. In: Specialty Corns, $1^{\text {st }}$ ed., Hallauer, A.R. Eds., CRC Press, Inc., Boca Raton, Florida.

Hanashiro, I.; Itoh, K.; Kuratomi, Y.; Yamazaki, M.; Igarashi, T.; Matsugasako, J.; Takeda, Y. (2008). Granule-bound starch synthase I is responsible for biosynthesis of extra-long unit chains of amylopectin in rice. Plant Cell Physiology 49, 925-933.

Hermansson, A.M.; \& Svegmark, K. (1996). Developments in the understanding of starch functionality. Trends in Food Science and Technology 7, 345-353.

322 Hoseney, R.C.; Zeleznak, K.J.; \& Yost, D.A. (1986). A note on the gelatinization of starch. Starch 12, 407-409.

Jane, J. (2006). Current understanding on starch granule structures. Journal of Applied Glycoscience 53, 205-213.

Jane, J. (2007). Structures of starch granules. Journal of Applied Glycoscience 54, 31-36.

327 Jane, J. \& Chen, J-F. (1992). Effect of amylose molecular size and amylopectin branch chain length of paste properties of starch. Cereal Chemistry 69, 60-65.

Jane, J.; Chen, Y. Y.; Lee, L. F.; McPherson, A. E.; Wong, K. S.; Radosavljevic, M.; \& Kasemsuwan, T. (1999). Effects of amylopectin branch-chain length and amylose content on the gelatinization and pasting properties of starch. Cereal Chemistry 76, 629-

333 Jiang, H.; Campbell, M.; Blanco, M.; \& Jane, J. (2010). Characterization of maize amyloseextender (ae) mutant starches: Part II. Structures and properties of starch residues remaining after enzymatic hydrolysis at boiling-water temperature. Carbohydrate Polymers 80, 1-12. 
337 Kitahara, K.; Hamasuna, K.; Nozuma, K.; Otani, M.; Hamada, T.; Shimada, T.; Fujita, K.; \& Suganuma, T. (2007). Physicochemical properties of amylose-free and high-amylose starches from transgenic sweetpotatoes modified by RNA interference. Carbohydrate Polymer 69, 233-240.

Li, L., Jiang, H., Campbell, M., Blanco, M., \& Jane, J. (2008). Characterization of maize amylose-extender (ae) mutant starches. Part I: Relationship between resistant starch contents and molecular structures. Carbohydrate Polymer 74, 396-404.

Miura, H.; Wichramasinghe, M.H.A.; Subasinghe, R.M.; Araki, E.; \& Komae, K. (2002). Development of near-isogenic lines of wheat carrying different null $\mathrm{Wx}$ alleles and their starch properties. Euphytica 123, 353-359.

Sasaki, T.; Yasui, T.; \& Matsuki, J. (2000). Effects of amylose content on gelatinization, retrogradation, and pasting properties of starches from waxy and nonwaxy wheat and their F1 seeds. Cereal Chemistry 77, 58-63.

Schoch, T.J. (1942). Fractionation of starch by selective precipitation with butanol. Journal of American Chemical Society 64, 2957-2961.

Song, Y.; \& Jane, J. (2000). Characterization of barley starches of waxy, normal, and high amylose varieties. Carbohydrate Polymers 41, 365-377.

Takeda, Y., \& Hizukuri, S. (1987). Structures of rice amylopectins with low and high affinities for iodine. Carbohydrate Research 168, 79-88.

Takeda, Y.; Tomooka, S.; and Hizukuri, S. (1993). Structures of branched and linear-molecules of rice amylose. Carbohydrate Research 246, 267-272.

Tester, R.F.; Karkalas, J.; \& Qi, X. (2004). Starch - composition, fine structure and architecture. Journal of Cereal Science 39, 151-165. 
360 Tsai, C-Y. (1974). The function of the Waxy locus in starch synthesis in maize endosperm.

$361 \quad$ Biochemical Genetics 11, 83-96.

362 USDA ERS. (2015). Corn - Background. (URL:

363 http://www.ers.usda.gov/topics/crops/corn/background.aspx\#.Uwt 0IU18qM)

364 Wickramasinghe, H.A.M. \& Miura, H. (2003) Gene dosage effect of the wheat Wx alleles and 365 their interaction on amylose synthesis in the endosperm. Euphytica 132, 303-310.

366 Yasui, T.; Ashida, K.; \& Sasaki, T. (2009). Chain-length distribution profiles of amylopectin 367 isolated from endosperm starch of waxy and low-amylose bread wheat (Triticum

368 aestivum L.) lines with common genetic background. Starch 61, 677-686.

369 Yoo, S-H. \& Jane, J. (2002a). Structural and physical characteristics of waxy and other wheat $370 \quad$ starches. Carbohydrate Polymers 49, 297-305.

371 Yoo, S-H. \& Jane, J. (2002b). Molecular weights and gyration radii of amylopectins determined 372 by high-performance size-exclusion chromatography equipped with multi-angle laser373 light scattering and refractive index detectors. Carbohydrate Polymers 49, 307-314. 


\section{FIGURE CAPTIONS}

375

376 Figure 1. Amylopectin branch-chain length distribution of the corn starches with different

377 dosages of the Waxy gene. The chromatograms indicate the changes of RI signal intensities over

378 time. The RI signals have been normalized using the total peak area of the curves. The Set 1

379 samples included the pedigree DKXL370:N11a20-036-002, and the Set 2 samples included the

380 pedigree AR16035:S02-615-001. Dosages of the Waxy gene for samples wx, wx $\times \mathrm{N}, \mathrm{N} \times \mathrm{wx}$,

381 and $\mathrm{N}$ were $0,1,2$, and 3 , respectively.

382

383 Figure 2. Starch pasting properties of the corn starches with different dosages of the Waxy gene.

384 The Set 1 samples included the pedigree DKXL370:N11a20-036-002, and the Set 2 samples

385 included the pedigree AR16035:S02-615-001. Dosages of the Waxy gene for samples wx, wx $\times$

$386 \mathrm{~N}, \mathrm{~N} \times \mathrm{wx}$, and $\mathrm{N}$ were $0,1,2$, and 3 , respectively. 


\section{TABLE CAPTIONS}

388

389 Table 1. Pedigree, genotype, and Waxy-gene dosage of the endosperm of the GEM corn samples 390

391 Table 2. Amylose and lipid contents of starch and amylose molecular-weight of the corn

392 starches with different dosages of the Waxy gene

393

394 Table 3. Amylopectin molecular-weight and gyration radii of the corn starches with different

395 dosages of the Waxy gene

396

397 Table 4. Amylopectin branch-chain length distribution of the corn starches with different

398 dosages of the Waxy gene

399

400 Table 5. Starch thermal-properties of the corn starches with different dosages of the Waxy gene 401

402 Table 6. Starch pasting-properties of the corn starches with different dosages of the Waxy gene 
Table 1. Pedigree, genotype, and Waxy-gene dosage of the endosperm of the GEM corn samples

\begin{tabular}{|c|c|c|c|c|}
\hline & Sample $^{a}$ & Pedigree & Genotype of endosperm & Waxy-gene dosage \\
\hline \multirow{4}{*}{ Set 1} & wx & DKXL370:N11a20-036-002-B wx & $w X w X w X$ & 0 \\
\hline & $\mathrm{wx} \times \mathrm{N}$ & $\begin{array}{l}\text { DKXL370:N11a20-036-002-B wx } \times \\
\text { DKXL370:N11a20-036-002-B-B-B-B }\end{array}$ & $w x w x W x$ & 1 \\
\hline & $\mathrm{N} \times w \mathrm{x}$ & $\begin{array}{l}\text { DKXL370:N11a20-036-002-B-B-B-B × } \\
\text { DKXL370:N11a20-036-002-B wx }\end{array}$ & $w x W x W x$ & 2 \\
\hline & $\mathrm{N}$ & DKXL370:N11a20-036-002-B-B-B-B & $W x W x W x$ & 3 \\
\hline \multirow{4}{*}{ Set 2} & wx & AR16035:S02-615-001-B wx & $w X w X w X$ & 0 \\
\hline & $\mathrm{wx} \times \mathrm{N}$ & $\begin{array}{l}\text { AR16035:S02-615-001-B wx } \times \\
\text { AR16035:S02-615-001-B-B-B-B }\end{array}$ & $w x w x W x$ & 1 \\
\hline & $\mathrm{N} \times \mathrm{wx}$ & $\begin{array}{l}\text { AR16035:S02-615-001-B-B-B-B × } \\
\text { AR16035:S02-615-001-B wx }\end{array}$ & $w x W x W x$ & 2 \\
\hline & $\mathrm{N}$ & AR16035:S02-615-001-B-B-B-B & $W x W x W x$ & 3 \\
\hline
\end{tabular}

$\overline{a_{\mathrm{wX}}}=$ waxy corn $; \mathrm{N}=$ normal corn. In each case the female parent line appears first and has the endosperm genotype. 
Table 2. Amylose and lipid contents of starch and average molecular-weight of amylose of the corn starches with different dosages of the Waxy gene ${ }^{a}$

\begin{tabular}{ccccccc}
\hline Sample & $\begin{array}{c}\text { Waxy } \\
\text { gene } \\
\text { dosage }\end{array}$ & $\begin{array}{c}\text { Amylose } \\
(\%)\end{array}$ & $\begin{array}{c}\text { Relative } \\
\text { amylose } \\
\text { content }\end{array}$ & $\begin{array}{c}\text { Average } \\
\text { molecular- } \\
\text { weight of } \\
\text { amylose (DP) }\end{array}$ & $\begin{array}{c}\text { Lipid } \\
(\%)\end{array}$ \\
\hline \multirow{2}{*}{ Set 1} & $\mathrm{wx}$ & 0 & $1.6 \mathbf{d} \pm 0.0$ & $6 \%$ & $\mathrm{~N} / \mathrm{A}^{\mathbf{b}}$ & $0.24 \mathbf{c} \pm 0.06$ \\
& $\mathrm{~N} \times \mathrm{N}$ & 1 & $20.9 \mathbf{c} \pm 0.1$ & $75 \%$ & $640.5 \mathbf{a} \pm 10.3$ & $0.75 \mathbf{a b} \pm 0.02$ \\
& $\mathrm{~N} \times \mathrm{wx}$ & 2 & $22.4 \mathbf{b} \pm 0.4$ & $80 \%$ & $651.3 \mathbf{a} \pm 16.4$ & $0.84 \mathbf{a} \pm 0.05$ \\
& $\mathrm{Wx}$ & 0 & $0.0 \mathbf{d} \pm 0.0$ & $0 \%$ & $\mathrm{~N} / \mathrm{A}$ & $0.10 \mathbf{c} \pm 0.00$ \\
Set 2 & $\mathrm{Wx} \times \mathrm{N}$ & 1 & $20.0 \mathbf{c} \pm 0.1$ & $75 \%$ & $644.2 \mathbf{a} \pm 8.2$ & $0.74 \mathbf{a} \pm 0.04$ \\
& $\mathrm{~N} \times \mathrm{wx}$ & 2 & $21.5 \mathbf{b} \pm 0.1$ & $81 \%$ & $646.1 \mathbf{a} \pm 9.7$ & $0.84 \mathbf{a} \pm 0.07$ \\
& $\mathrm{~N}$ & 3 & $26.6 \mathbf{a} \pm 0.2$ & $100 \%$ & $637.8 \mathbf{a} \pm 1.8$ & $0.55 \mathbf{b} \pm 0.03$ \\
\hline
\end{tabular}

${ }^{\bar{a}}$ Values are means \pm standard deviations of two replicates. Different letters following the mean values within the same columns indicate statistically different mean values within each set of the corn starch samples $(\mathrm{p}<0.05)$. The Set 1 samples included the pedigree DKXL370:N11a20-036002, and the Set 2 samples included the pedigree AR16035:S02-615-001. ${ }^{\boldsymbol{b}}$ Not available. 
Table 3. Amylopectin molecular-weight and gyration radii of the corn starches with different dosages of the Waxy gene ${ }^{a}$

\begin{tabular}{cccc}
\hline & Sample & $\mathrm{M}_{\mathrm{w}}\left(\times 10^{8} \mathrm{~g} / \mathrm{mol}\right)$ & $\mathrm{R}_{\mathrm{z}}(\mathrm{nm})$ \\
\hline & $\mathrm{wx}$ & $11.8 \mathbf{a} \pm 0.2$ & $380.0 \pm 1.4$ \\
Set 1 & $\mathrm{wx} \times \mathrm{N}$ & $10.3 \mathbf{b} \pm 0.6$ & $362.3 \pm 5.9$ \\
& $\mathrm{~N} \times \mathrm{wx}$ & $9.5 \mathbf{b} \pm 0.2$ & $355.4 \pm 1.3$ \\
& $\mathrm{~N}$ & $10.1 \mathbf{b} \pm 0.0$ & $363.0 \pm 0.8$ \\
\hline & $\mathrm{wx}$ & $12.4 \mathbf{a} \pm 0.4$ & $387.4 \pm 5.6$ \\
\multirow{3}{*}{ Set 2 } & $\mathrm{wx} \times \mathrm{N}$ & $10.5 \mathbf{a} \pm 0.7$ & $368.2 \pm 7.9$ \\
& $\mathrm{~N} \times \mathrm{wx}$ & $11.7 \mathbf{a} \pm 0.6$ & $380.2 \pm 15.8$ \\
& $\mathrm{~N}$ & $11.1 \mathbf{a} \pm 0.4$ & $376.3 \pm 4.9$ \\
\hline
\end{tabular}

${ }^{\bar{a}}$ Values are means \pm standard deviations of two replicates. Different letters following the mean values within the same columns indicate statistically different mean values within each set of the corn starch samples $(\mathrm{p}<0.05)$. The Set 1 samples included the pedigree DKXL370:N11a20-036002, and the Set 2 samples included the pedigree AR16035:S02-615-001. Dosages of the Waxy gene for samples $w x, w x \times N, N \times w x$, and $\mathrm{N}$ were $0,1,2$, and 3 , respectively. 
Table 4. Amylopectin branch-chain length distribution of the corn starches with different dosages of the Waxy gene ${ }^{a}$

\begin{tabular}{ccccccc}
\hline & Sample & $\mathrm{DP}<17$ & $\mathrm{DP} 17-30$ & $\mathrm{DP} 30-80$ & $\mathrm{DP} 80-100$ & $\mathrm{DP}>100$ \\
\hline & $\mathrm{wx}$ & $51.0 \mathbf{a} \pm 0.5$ & $30.0 \mathbf{d} \pm 0.2$ & $17.9 \mathbf{a} \pm 0.2$ & $0.9 \mathbf{a} \pm 0.1$ & $0.2 \mathbf{d} \pm 0.0$ \\
\multirow{3}{*}{ Set 1 } & $\mathrm{wx} \times \mathrm{N}$ & $50.4 \mathbf{a b} \pm 0.3$ & $30.8 \mathbf{c} \pm 0.1$ & $17.3 \mathbf{b} \pm 0.1$ & $0.9 \mathbf{a} \pm 0.1$ & $0.6 \mathbf{c} \pm 0.0$ \\
& $\mathrm{~N} \times \mathrm{wx}$ & $49.8 \mathbf{b} \pm 0.4$ & $31.6 \mathbf{b} \pm 0.2$ & $16.7 \mathbf{c} \pm 0.2$ & $0.9 \mathbf{a} \pm 0.0$ & $1.0 \mathbf{b} \pm 0.1$ \\
& $\mathrm{~N}$ & $47.3 \mathbf{c} \pm 0.2$ & $33.5 \mathbf{a} \pm 0.0$ & $16.2 \mathbf{c} \pm 0.2$ & $1.0 \mathbf{a} \pm 0.0$ & $2.0 \mathbf{a} \pm 0.0$ \\
\hline & $\mathrm{wx}$ & $49.9 \mathbf{a} \pm 0.3$ & $31.2 \mathbf{d} \pm 0.1$ & $17.8 \mathbf{a} \pm 0.1$ & $0.8 \mathbf{a} \pm 0.1$ & $0.3 \mathbf{c} \pm 0.0$ \\
\multirow{3}{*}{ Set 2 } & $\mathrm{wx} \times \mathrm{N}$ & $49.3 \mathbf{a} \pm 0.3$ & $33.0 \mathbf{c} \pm 0.1$ & $15.6 \mathbf{b} \pm 0.0$ & $0.9 \mathbf{a} \pm 0.1$ & $1.2 \mathbf{b} \pm 0.0$ \\
& $\mathrm{~N} \times \mathrm{wx}$ & $47.3 \mathbf{b} \pm 0.5$ & $35.6 \mathbf{b} \pm 0.4$ & $14.8 \mathbf{c} \pm 0.0$ & $0.9 \mathbf{a} \pm 0.1$ & $1.4 \mathbf{b} \pm 0.0$ \\
& $\mathrm{~N}$ & $46.1 \mathbf{c} \pm 0.3$ & $37.4 \mathbf{a} \pm 0.3$ & $14.0 \mathbf{d} \pm 0.1$ & $0.7 \mathbf{a} \pm 0.1$ & $1.8 \mathbf{a} \pm 0.0$ \\
\hline
\end{tabular}

${ }^{a}$ Weight averaged. Values are means \pm standard deviations of two replicates. Different letters following the mean values within the same columns indicate statistically different mean values within each set of the corn starch samples $(\mathrm{p}<0.05)$. The Set 1 samples included the pedigree DKXL370:N11a20-036-002, and the Set 2 samples included the pedigree AR16035:S02-615001. Dosages of the Waxy gene for samples $\mathrm{wx}, \mathrm{wx} \times \mathrm{N}, \mathrm{N} \times \mathrm{wx}$, and $\mathrm{N}$ were $0,1,2$, and 3 , respectively. 
Table 5. Starch thermal-properties of the corn starches with different dosages of the Waxy gene ${ }^{a}$

\begin{tabular}{ccccccc}
\hline & Sample & $\mathrm{T}_{\mathrm{o}}{ }^{b}\left({ }^{\circ} \mathrm{C}\right)$ & $\mathrm{T}_{\mathrm{p}}\left({ }^{\circ} \mathrm{C}\right)$ & $\mathrm{T}_{\mathrm{c}}\left({ }^{\circ} \mathrm{C}\right)$ & $\Delta \mathrm{H}(\mathrm{J} / \mathrm{g})$ & $\mathrm{T}_{\mathrm{c}}-\mathrm{T}_{\mathrm{o}}\left({ }^{\circ} \mathrm{C}\right)$ \\
\hline & $\mathrm{wx}$ & $65.7 \mathbf{a b} \pm 0.0$ & $71.8 \pm 0.1$ & $77.0 \mathbf{a} \pm 0.4$ & $14.0 \mathbf{a} \pm 0.1$ & $11.2 \mathbf{a} \pm 0.4$ \\
Set 1 & $\mathrm{wx} \times \mathrm{N}$ & $66.1 \mathbf{a} \pm 0.1$ & $71.3 \pm 0.1$ & $75.9 \mathbf{b} \pm 0.0$ & $12.3 \mathbf{b} \pm 0.1$ & $9.7 \mathbf{b} \pm 0.1$ \\
& $\mathrm{~N} \times \mathrm{wx}$ & $65.2 \mathbf{c} \pm 0.1$ & $69.9 \pm 0.1$ & $74.7 \mathbf{c} \pm 0.2$ & $12.0 \mathbf{c} \pm 0.1$ & $9.5 \mathbf{b} \pm 0.3$ \\
& $\mathrm{~N}$ & $65.6 \mathbf{b} \pm 0.0$ & $69.7 \pm 0.0$ & $74.4 \mathbf{c} \pm 0.1$ & $11.9 \mathbf{c} \pm 0.0$ & $8.8 \mathbf{b} \pm 0.0$ \\
\hline & $\mathrm{wx}$ & $62.3 \mathbf{a} \pm 0.1$ & $68.9 \pm 0.0$ & $74.4 \mathbf{a} \pm 0.0$ & $13.2 \mathbf{a} \pm 0.1$ & $12.1 \mathbf{a} \pm 0.2$ \\
\multirow{3}{*}{ Set 2 } & $\mathrm{wx} \times \mathrm{N}$ & $62.2 \mathbf{a} \pm 0.1$ & $68.4 \pm 0.0$ & $73.5 \mathbf{b} \pm 0.1$ & $11.6 \mathbf{b} \pm 0.0$ & $11.3 \mathbf{b} \pm 0.1$ \\
& $\mathrm{~N} \times \mathrm{wx}$ & $62.3 \mathbf{a} \pm 0.2$ & $67.7 \pm 0.1$ & $72.4 \mathbf{c} \pm 0.0$ & $11.6 \mathbf{b} \pm 0.0$ & $10.1 \mathbf{c} \pm 0.3$ \\
& $\mathrm{~N}$ & $62.5 \mathbf{a} \pm 0.0$ & $67.4 \pm 0.1$ & $72.0 \mathbf{d} \pm 0.1$ & $11.2 \mathbf{c} \pm 0.1$ & $9.5 \mathbf{c} \pm 0.1$ \\
\hline
\end{tabular}

${ }^{a}$ Values are means \pm standard deviations of two replicates. Different letters following the mean values within the same columns indicate statistically different mean values within each set of the corn starch samples $(\mathrm{p}<0.05)$. The Set 1 samples included the pedigree DKXL370:N11a20-036002, and the Set 2 samples included the pedigree AR16035:S02-615-001. Dosages of the Waxy gene for samples $\mathrm{wx}, \mathrm{wX} \times \mathrm{N}, \mathrm{N} \times \mathrm{wx}$, and $\mathrm{N}$ were $0,1,2$, and 3 , respectively. ${ }^{b} \mathrm{~T}_{\mathrm{o}}=$ onset gelatinization temperature, $\mathrm{T}_{\mathrm{p}}=$ peak temperature, $\mathrm{T}_{\mathrm{c}}=$ conclusion temperature, $\Delta H=$ enthalpy change. 
Table 6. Starch pasting-properties of the corn starches with different dosages of the Waxy gene ${ }^{a}$

\begin{tabular}{cccccccc}
\hline & Sample & $\begin{array}{c}\text { Pasting } \\
\text { Temp. }\left({ }^{\circ} \mathrm{C}\right)\end{array}$ & Peak (RVU) & Hold (RVU) & Final (RVU) & $\begin{array}{c}\text { Breakdown } \\
(\mathrm{RVU})\end{array}$ & $\begin{array}{c}\text { Setback } \\
(\mathrm{RVU})\end{array}$ \\
\hline \multirow{3}{*}{ Set 1} & $\mathrm{wx}$ & $71.0 \mathbf{b} \pm 0.3$ & $217.3 \mathbf{a} \pm 4.0$ & $78.3 \mathbf{b} \pm 1.6$ & $101.8 \mathbf{d} \pm 2.9$ & $138.9 \mathbf{a} \pm 2.4$ & $23.4 \mathbf{d} \pm 1.3$ \\
& $\mathrm{wx} \times \mathrm{N}$ & $73.8 \mathbf{a} \pm 0.3$ & $147.8 \mathbf{b} \pm 2.2$ & $73.6 \mathbf{c} \pm 2.4$ & $142.1 \mathbf{c} \pm 2.2$ & $74.2 \mathbf{b} \pm 0.2$ & $68.5 \mathbf{c} \pm 0.2$ \\
& $\mathrm{~N} \times \mathrm{wx}$ & $72.3 \mathbf{a b} \pm 0.6$ & $150.2 \mathbf{b} \pm 2.5$ & $75.1 \mathbf{b c} \pm 1.2$ & $148.7 \mathbf{b} \pm 1.5$ & $75.1 \mathbf{b} \pm 1.2$ & $73.5 \mathbf{b} \pm 0.3$ \\
& $\mathrm{~N}$ & $71.4 \mathbf{b} \pm 0.3$ & $157.6 \mathbf{b} \pm 1.2$ & $90.4 \mathbf{a} \pm 0.8$ & $182.8 \mathbf{a} \pm 0.6$ & $67.2 \mathbf{c} \pm 1.9$ & $92.5 \mathbf{a} \pm 1.4$ \\
\hline \multirow{3}{*}{ Set 2 } & $\mathrm{wx}$ & $69.0 \mathbf{c} \pm 0.3$ & $221.0 \mathbf{a} \pm 0.7$ & $72.0 \mathbf{c} \pm 1.7$ & $102.1 \mathbf{d} \pm 0.6$ & $148.9 \mathbf{a} \pm 1.1$ & $30.1 \mathbf{d} \pm 1.1$ \\
& $\mathrm{wx} \times \mathrm{N}$ & $72.3 \mathbf{a} \pm 0.0$ & $149.9 \mathbf{b} \pm 2.7$ & $74.1 \mathbf{c} \pm 0.6$ & $146.8 \mathbf{c} \pm 1.6$ & $75.8 \mathbf{b} \pm 2.1$ & $72.7 \mathbf{c} \pm 2.2$ \\
& $\mathrm{~N} \times \mathrm{wx}$ & $72.5 \mathbf{a} \pm 0.2$ & $143.6 \mathbf{b} \pm 1.4$ & $84.9 \mathbf{b} \pm 1.7$ & $169.8 \mathbf{b} \pm 2.1$ & $58.7 \mathbf{c} \pm 0.3$ & $84.9 \mathbf{b} \pm 3.8$ \\
& $\mathrm{~N}$ & $71.3 \mathbf{b} \pm 0.3$ & $148.3 \mathbf{b} \pm 0.7$ & $95.6 \mathbf{a} \pm 0.4$ & $202.2 \mathbf{a} \pm 2.0$ & $52.5 \mathbf{d} \pm 0.1$ & $106.6 \mathbf{a} \pm 2.4$ \\
\hline
\end{tabular}

${ }^{a}$ Values are means \pm standard deviations of two replicates. Different letters following the mean values within the same columns indicate statistically different mean values within each set of the corn starch samples $(\mathrm{p}<0.05)$. The Set 1 samples included the pedigree DKXL370:N11a20-036-002, and the Set 2 samples included the pedigree AR16035:S02-615-001. Dosages of the Waxy gene for samples wx, wx $\times \mathrm{N}, \mathrm{N} \times \mathrm{wx}$, and $\mathrm{N}$ were $0,1,2$, and 3, respectively. RVU $=$ Rapid-visco unit(s). 
Figure 1
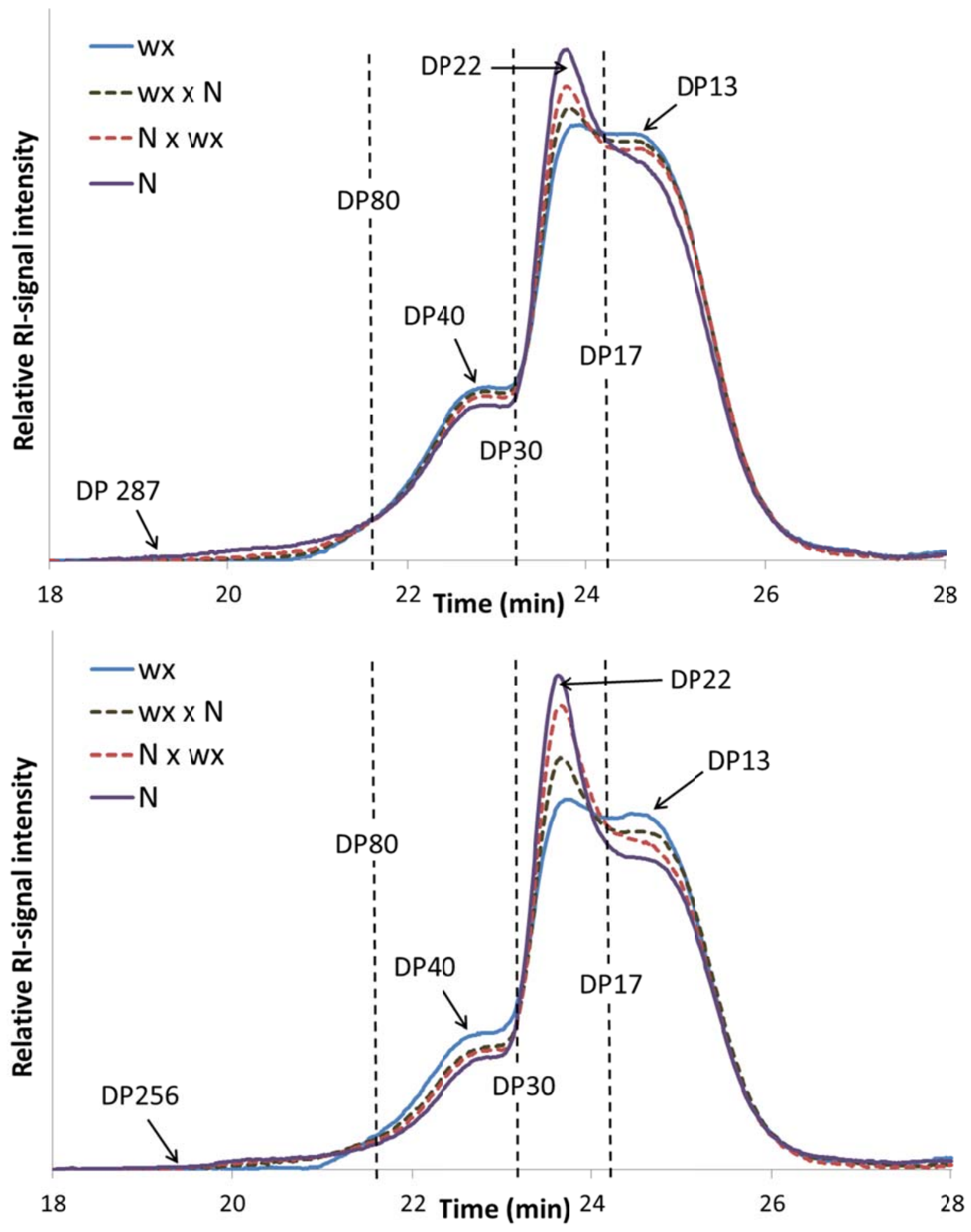
Figure 2

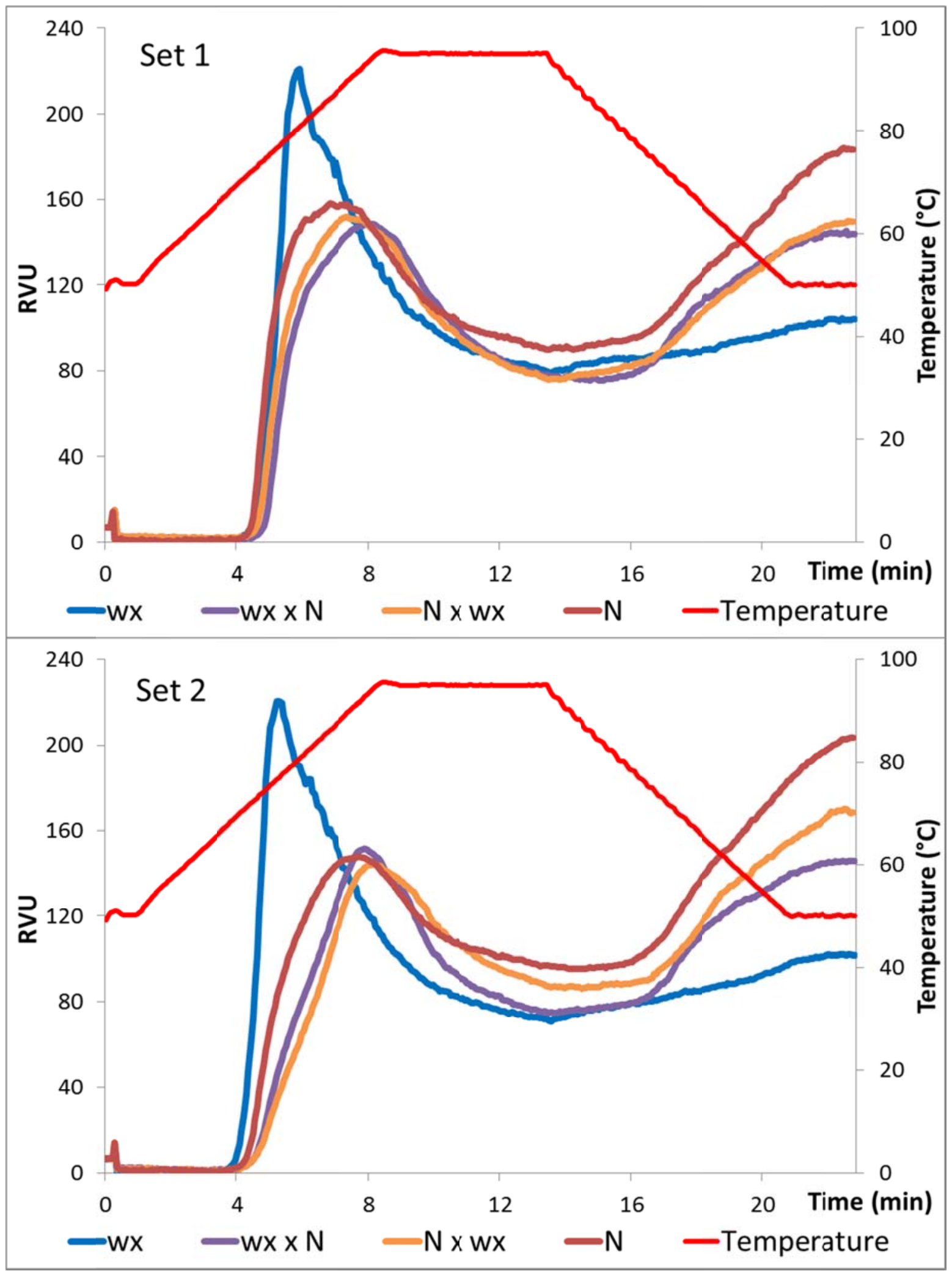

